\title{
El Origen del Nombre de América está en Nicaragua
}

$\mathrm{SE}^{\mathrm{E}}$ debe a muchas circunstancias el no haber dado la trascendencia $S$ debida al hecho de señalar un rincón del centro continental como origen del nombre de América. Pero son varios los investigadores que persisten en el importante descubrimiento.

En primer término, la falta de publicidad o, mejor dicho, la escasa fuerza de la publicidad en este sentido, no ha prestado facilidades a quienes, desde otros países, podrían dedicarse a seguir el hilo de las investigaciones. El ombligo de la cuestión queda en un país sin propaganda, mejor conocido por sus pasados desórdenes políticos que por sus vastos recursos naturales, guardando la proporción de sus dimensiones geográficas. La aludida zona está en lugares inexplotados e inexplorados, como es, puede decirse, casi toda la República de Nicaragua. Y cuando se ha llegado a la Sierra de Amerrique, enclavada en lo abrupto del departamento o provincia de Chontales, nos convencemos de que no son verdaderos arqueólogos los que han excavado en sus tierras, bajo sus ruinas. El examen ha sido superficial, empírico, como lo ha sido una que otra discusión sobre el problema del origen del nombre de América en Nicaragua.

E1 país, de ciento cincuenta mil kilómetros cuadrados, con un millón de habitantes, más o menos, está dividido en las dos vertientes comunes a la mayor parte de las naciones americanas: la del Atlántico y la del Pacífico. El eje, la cima dominadora, la atalaya que puede considerarse como una de las estribaciones menores de la vertebral Cordillera de los Andes, es la Sierra de Amerrique. Desde ella, en determinados momentos, pueden contemplarse los dos océanos. Con la frente del observador al Norte, a la derecha queda el 
mar de las carabelas de Colón; a la izquierda, el inmenso océano que descubrió un poco más al sur Vasco Núñez de Balboa; de cerrazón vegetal, casi salvaje y en verdes llanuras inundadas, con un poderoso sistema hidrográfico la del Atlántico; en declives más escarpados la del Pacífico; árida de por sí, con el vientre hirviendo de lava en la perfecta línea andina de los veinte volcanes, desde el Cosigüina en el bellísimo Golfo de Fonseca, hasta los gemelos de las islas del Gran Lago, llamado Mar Dulce por los aborígenes y los conquistadores.

En las montañas de la vertiente del Pacífico hay escaso oro. En las del Atlántico abunda, hasta ser arrastradas todavia las pepitas de varias onzas por los grandes ríos que van a dar al Caribe. Grandes aluviones de oro iban desde las laderas de la Sierra de Amerrique hasta las costas saladas del Oriente, como en busca y para el homenaje al Dios-Sol que por ese lado se asomaba todos los días. Bajaban de Amerrique los nativos de la región, con cargas de metal amarillo. "Los hombres de los espejos de oro" los llamaban los cronistas del descubrimiento, porque eran de oro los espejos que ellos cambiaban por bagatelas. Ajorcas de oro hasta en los tobillos descalzos, collares de oro en las gargantas, pendientes de oro de los lóbulos de las orejas y de las narices, canutos de polvo de oro que iban desde Amerrique a pagar el tributo al poderoso Señor Moctezuma en la capital azteca, transportados por correos de relevo, los mismos que llevaban todavía palpitantes y frescos los peces de las bahías y de los ríos centroamericanos para la mesa del Emperador, a centenares de leguas de distancia.

Ahora bien: como casi todas las incursiones conquistadoras procedieron del Norte, de México llegaron las principales a lo que hoy es Centroamérica, así como del Norte llegaron a fundar Tenochtitlán (la capital mexicana) los guerreros de Aztlán. Del Norte llegaron (márgenes del Mississippi) los mayas que fueron más abajo, hasta la península esotérica de Yucatán, que cierra como pinza de tenaza al hoy Golfo de México.

En Nicaragua se bifurcaron las dos corrientes norteñas, obedeciendo a la situación geográfica. Es innegable la influencia de la cultura mexicana en la región del Pacífico, con las costumbres de las ramas toltecas y sus familias ya degeneradas en pipiles, chorotegas, etc. Existen voces comunes, raíces fonéticas, terminaciones. $Y$, por otra parte, es innegable la cultura o influencia maya en la zona del 
Atlántico, dentro de la que podemos situar las estribaciones o, más bien, los declives de la Sierra de Amerrique. Escasos exploradores no arqueólogos han recorrido con rudimentarios conocimientos de enlace racial esos sitios: y han descubierto que coincide la naturaleza de los restos de la cultura local con los de la cultura maya que bajara desde la Península de Yucatán - trono de los itzaes- pasando antes por el hoy Estado de Campeche, el departamento guatemalteco de Petén y la zona de Copán, en Honduras. No se ha estudiadio en Amerrique, de lo que se deduce que alli terminó con débiles aspectos la civilizada corriente de los mayas. Tal vez las pruebas de esa civilización, por lo que toca a la región nicaragüense de Amerrique, estén sepultadas por las capas de tierra que acumulan los siglos, como en estos años han aparecido, desenterrados, los palacios de cien columnas, los campos de juego de pelota, los templos del Adivino y de las Monjas en Chichén Itzá y Uxmal de las regiones yucatecas.

Amerrique o Amerriskín está traducido del maya con el concepto clásico de "Tierra de los Fuertes Vientos" y no faltan otros que lo vierten asi: "Tierra del Sol Brillante". Pero uno y otro concepto corresponden a la naturaleza del lugar: soplan allí recios ventarrones y el Sol es ardiente. Recientes descubrimientos de viajeros curiosos han probado la similitud de los ídolos mayas con la alfarería chontaleña desenterrada en Amerrique. De seguro que si se excavara en los montículos podría llegarse al descubrimiento de edificios bajo la capa de polvo de milenios, como, lo repetimos, aconteció en Yucatán bajo la paciente labor del doctor Morley, que destruyó - limpió pretendidos cerros para hacer surgir de sus entrañas las inequívocas muestras de una civilización, con arquitectura sólo comparable a la egipcia, con astronomía y leyes físicas y humanas.

De este modo, la cultura de América, aun descendiendo desde las cuencas del Mississippi, queda dentro de la hoya del Mediterráneo de América: el actual Golfo de México. Toda la costa oriental de esta nación y los territorios de los Estados Unidos, desde la simétrica península de Florida que hace digno pendant con su hermana la península de Yucatán, encierran la cuna de una gran civilización en el continente.

Es indudable que el Golfo de México es el Mediterráneo de América. Las diversas conmociones geológicas to limitaron a lo que hoy aceptamos como Golfo; pero éste es mediterráneo, no obstante las salidas marítimas que quedan entre la Florida y Cuba y entre 
esta isla y las Antillas Menores. Mas, en substancia, para el observador que no se ciñe a la exactitud material para sus observaciones, para sus deducciones, esos promontorios de tierra que aún quedan no son sino las eminencias de unas porciones mayores que se hundieron en su parte inferior a causa de los cataclismos. Cada día se acentúa la certeza de la Atlántida.

Esta cultura americana tenía sus ejecutorias en Yucatán, en Petén y en Copán, con obra del hombre. En Amerrique se disfrutaba de la riqueza natural con el oro que hasta se derramaba por los ríos. Ya nos hemos referido al tributo que, muchos siglos después de las invasiones, llegaba a los emperadores aztecas desde la serranía de Amerrique, cuando el arma conquistadora de los habitantes de la meseta de Anáhuac se desbordó por Tehuantepec en tiempos de Ahuitzotl y sometió por las buenas y por las malas a los zapotecas, yendo más allá, hasta los límites del istmo americano.

Nuestro Mediterráneo posiblemente se cerraba por la parte suroriental, frente a Venezuela, y no fué sino hasta varios siglos después cuando quedó circunscrito a lo que hoy se conoce propiamente con el nombre de Golfo de México. Yucatán misma no existía en esos principios: no fué sino producto de una fuerza equilibradora y monstruosa, de un acomodamiento surgiendo de las profundidades líquidas para compensar el hundimiento de las tierras ahogadas más al Oriente, de las que sólo han quedado las cimas como las Grandes y Pequeñas Antillas, las Bahamas, etc. La naturaleza del suelo yucateco prueba que es tierra que surgió del mar: extensión árida, sin ríos visibles, cubierta por arena y capas calcáreas y en donde a muchos kilómetros de lo que hoy es costa se han hallado restos oceánicos, como conchas de moluscos y hasta esqueletos fosilizados de seres maritimos.

Todo esto es gigantesco, casi fantástico, como resulta la coincidencia del maravilloso ensamble del continente africano con el suramericano: cuenca aquí en lo que es saliente allá y viceversa, con una exactitud geométrica que afirma la teoría de un desprendimiento inmenso, de disgregación de un todo, que permitió la entrada de las aguas atlánticas en las junturas, separando lo que todavía tiene la misma flora, idéntica fauna y rasgos raciales comunes, un poco alterados aparentemente por las condiciones exteriores de vida, como el clima y los alimentos. Africa y Suramérica tienen contrapartes que se encajan a perfección. 
Los mares mediterráneos han. sido el arranque de las civilizaciones en todos los tiempos. El de Europa marca el trascendental origen de la cultura occidental, desde cuando surcaban sus aguas las naves fenicias buscando mercado en el litoral del Oeste; esos fenicios que se guiaban por la marcha de las estrellas y llevaban su cultura al Africa, a España, a todos los lugares conocidos dentro de esa geografía del mar que se prestaba a las múltiples conquistas. Griegos y judíos se mezclan en -Alejandría, gracias al celestinaje del Mediterráneo. Roma, Atenas, Egipto, con sus vicios y sus glorias, con sus dioses y sus orgías, sus leyes y sus instintos, se abrazan gracias a la tolerancia del Mediterráneo. Sobre su lomo bogaron las galeras de los emperadores, con lágrimas de esclavos entre los tapices y la pedrería. Encima de sus aguas azules se mecieron las airosas trirremes y en sus vericuetos oía Ulises el armonioso canto de las sirenas. Su vaivén adormeció el cargamento de púrpura de Tiro, de perfumes de Arabia, de vino de Chipre, de flores de Alejandría, de las perlas del golfo de Ormuz.

Nuestro Mediterráneo es también centro de una admirable civilización y hay que aceptar la ley de la simetría a que obedecen los dos brazos líquidos en el Norte y en el Sur: el Mississippi, Padre de las Aguas, y el Amazonas, el más largo del mundo. La civilización maya quedó a cubierto entre estas dos cuencas e impuso su poder; pero cuando llegaron los españoles ya estaba en decadencia, casi había desaparecido hasta para no dejar jalones de su obra material. Pero algo quedaba flotando en la leyenda cuando desembarcaron los españoles; algo misterioso, como el humo de lo que fué grande: fábula de las fuentes de la eterna juventud, de Eldorados, de la Amerrique de donde bajaban los indigenas con espejos de oro. Amerriskín, Amerrique, América ... La leyenda cuaja en oro las montañas y no hay más que tomar una pica para desprender trozos áureos. Angeles o demonios custodian esos cerros, en donde sopla un fuerte viento y en donde brilla el sol perennemente. Todo eso era maya. Y la voz "América" es maya, por lo que significa arrancando de la montaña nicaragüense, por la importancia del oro que era el señuelo de los conquistadores, la obsesión del viaje y de la vida. Esto se llamaba "América" aun antes de que el hábito ciego se alimentara con la mescolanza italocastellana de Alberigo Vespucci.

Cuando este navegante florentino pone al pie de sus cartas - fetos incompletos de la geografía universal- su curiosa firma, no lo 
hacía como título de un cuadro ni con la intención de bautizar con su nombre las tierras recién descubiertas y que él recorría. No aspiraba a tanto, ni suponía la trascendencia de las confusiones que sobrevendrían. Suscribía sus mapas por una especie de propiedad artística, marca o sello de legitimidad. O quizá por vanidad. De todos modos, salvaba con su firma el derecho material, económico, poniendo su trabajo a salvo de los inescrupulosos copistas o plagiarios, tan de rapiña en esos tiempos. De nada vale el documento de Leonardo de Vinci, encontrado hace más de cincuenta años y que según algunos es el primero de los que se han encontrado, que llama "América" a esta parte del mundo. E1 público de todos los tiempos es influído por la fantasía y el europeo de aquella época obedece a la superstición. Fantasía es, a pesar de todo, el relato de Vespucio sobre los seis viajes hacia las tierras que recorrió de paso, pues sólo visitó las regiones costeras: va por Nicaragua, por el Golfo de México, hasta la bahía de Chesapeake y oye el cuento sorprendente, el milagro de las tierras floridas y salvajes, de los ríos que arrastran terrones de oro desde los cerros de oro macizo en la zona de Amerrique; de los pájaros que hablan; de los trozos de madera o leche de madera - el hule común-que brincan y danzan como si tuvieran ánima. Vespucio oye de labios de españoles, desorbitado por la fantasía y la avaricia, el cuento de Amerrique...

El nuevo Continente va y viene con las consejas a las que da pábulo. $Y$ en lo objetivo mucho se repara en los mapas trazados a ojo y en los que destaca la firma ampulosa del cartógrafo excursionista. E1 nuevo Continente va y viene en el libro de Vespucio Cuatro navegaciones. El mapa de Amerrique por Alberigo, Americo, Armerico, Alméric, Américus o Amergio...

La magnitud de la empresa descubridora y colonizadora diluye la localización de Amerrique con proezas estupendas: la conquista de México, el descubrimiento del otro océano, las intrigas y los crímenes en las expediciones, el aparatoso encadenamiento de Colón, las hazañas del Perú ... En el imperio incaico, sobre todo, no hay necesidad de exponerse a la asechanza de la legendaria montaña para conseguir el oro. Atahualpa puede llenar habitaciones enteras con el precioso metál, si así lo exigen los españoles de Pizarro. Los reyes nativos no usan segunda vez los platos de oro. Un telón amarillo y radioso está frente a las pupilas de los conquistadores aventureros, gente desheredada o venida a menos en Etropa. 
$\mathrm{Y}$ así se va perdiendo la importancia de la Sierra de Amerrique; pero el nombre queda grabado en las mentes, porque fué el primitivo y porque no hay fuerza mayor que el origen de los patronímicos para mantenerlos.

Es en el centro de América en donde está la clave de su propio nombre. El mismo Vespucio no intentaba arrebatar la gloria a Cristóbal Colón; los colombófilos de hoy sólo piensan en la escasa, o al menos incomparable por lo inferior, figuración de Vespucio, para que éste merezca la consagración de su nombre a un nuevo mundo. Vespucio no cuenta en esto. Algún día será aclarado convenientemente, quitando de los textos escolares, que son los que más influyen en las generaciones, esa mentira de la relación entre Alberico y América. Desde 1875 el Atlantic Monthly, en los Estados Unidos, publicó un interesante artículo en que se atribuye origen indígena al nombre de América. Pero el caso, si dió lugar a sátiras de los pretendidos sabios que lo adversaban, no les obligó a investigar en el terreno. Pesa mucho una leyenda de siglos de edad.

Un poderoso argumento contra la relación del nombre del cartógrafo y el de nuestro continente es el de que, aun aceptando que en honor de aquél se hubieran bautizado estas tierras, no habría correspondido el nombre de América al continente, sino el de Vespucio, pues los patronímicos eran los que servían de base a esos bautizos de tierras. Cuando Fernando Colón, hijo del Descubridor, observa los mapas de Vespucio, le da cartas de recomendación ante las autoridades de los dominios heredados de Colón y en ninguna de ellas se refiere a "América". Si se homenajeó a Vespucio, debería haberse llamado "Vespucia" o "Vespucina" la tierra innominada. Era el apellido del héroe el que prevalecía en la designación. Así tenemos a Colombia y no "Cristobalia" o cosa parecida; "Balboa" y no "Vascónida"; "Magallanes" y no "Fernandia", etc. Y si hubo "Isabelas" $y$ hay "Filipinas" y "Luisianas" es que debe tomarse en cuenta la característica de los nombres propios de los reyes, en los cuales el apellido desaparece. Pocos conocen los apellidos de Isabel, Luis, Felipe, etc. Y Américo Vespucio no era rey, para aceptar que desapareciera su apellido. De manera, pues, que no es por Américo, por honrarlo a él, por lo que se ha dado en llamar AméricA a esta parte del mundo. 
Resumiendo to anteriormente escrito y teniendo enfrente los libros y demás documentos en que nos apoyamos para este breve estudio, podemos afirmar abriendo un nuevo ciclo de discusión:

Vespucio no se llamaba "Américo", sino Alberigo y este último nombre no puede ser raíz de donde se derivara el de América. Afirman muchos historiadores que Jean Basin tomó "el nombre de un puerto por el de un hombre" y así quedó el nombre de un continente aplicado al cartógrafo. Jules Marcou es un acucioso investigador del asunto y con valor sostiene la tesis del origen del nombre de América en Nicaragua. El sostiene que "Vespucio el de América" sigue la costumbre del "Congo Stanley", descubridor del curso del Congo; del "Chino Gordon", sin haber sido éste chino. ¿No tuvo —dice Marcou- Roma a Escipión "El Africano" y otros por el estilo? Vespucio debe el nombre de Américo a América y no América se lo debe a Vespucio. Jean Basin era poeta editor, que tradujo al francés el libro en latín Las cuatro navegaciones.

Le Plongeon, que estudió a conciencia las lenguas indígenas, aseguró que América o Amerrique quiere decir en lengua maya: "país en donde el viento sopla con fuerza." $Y$ que la terminación maya "iqque", "ik" o "ika" no sólo significa "viento" sino "vida", "espíritu latente". Por eso algunos prefieren la traducción "Tierra del Sol Brillante", conforme a la adoración que al espíritu destinaban los indígenas todos del continente, en una concepción en honor al Sol.

Colón estuvo en Nicaragua, cerca de la Sierra de Amerrique, calafateando sus buques en el cuarto viaje y dando oportunidad a los más osados de sus marinos a que se internaran en las montañas vecinas, "montes de oro macizo". Eso fué del 16 al 24 de septiembre de 1502. Casi un año después, en julio, llegaron a La Española dos miembros de esa expedición, Méndez y Fiesco, contando las maravillas de Amerrique. No fué sino hasta fines de ese mismo año cuando en Europa se comenzó a hablar de Amerrique o de América y ya cuando Vespucio había trazado mapas con su firma. Tómese en cuenta que no es sino hasta 1507 cuando es bautizado el continente a propuesta del Gimnasio Vosguense, por moción del poeta y clérigo Basin.

$Y$ cerremos estas anotaciones con las muy oportunas del mismo Marcou:

En 1503, Vespucio dirige una carta a Médicis, firmándose $A l$ berico, del que nunca se puede derivar el nombre de América. 
La segunda carta de Vespucio, en 1504, ya va firmada Amerigo. Cuando muere Vespucio, en 1512, ya hacía cinco años que Jean Basin había impreso en Saint Dié los prenombres "Amerige" y "Americus" y el Gimnasio de marras propone se dé a la cuarta parte del mundo el nombre de América.

1515, Schöner declara que el nombre de América es generalmente usado.

$Y$ muere "el feliz impostor" florentino sin darse cuenta de la gloria que se le regala, por las confusiones de la época, por el ambiente de leyenda que prevalecía, por la sed de aventuras en pos del oro, de que era fantásticamente rica la región casi ignorada del centro montañoso de Nicaragua.

Hernán Robleto, Managua, Nicaragua. 
